ARTICLE

DOI: $10.1038 / s 41467-018-03403-9$

\title{
Elucidating anionic oxygen activity in lithium-rich layered oxides
}

Jing $\mathrm{Xu}^{1}$, Meiling Sun ${ }^{1}$, Ruimin Qiao ${ }^{2}$, Sara E. Renfrew ${ }^{3}$, Lu Ma ${ }^{4}$, Tianpin $\mathrm{Wu}^{4}$, Sooyeon Hwang ${ }^{5}$, Dennis Nordlund (D) ${ }^{6}$, Dong Su (D) ${ }^{5}$, Khalil Amine ${ }^{7}$, Jun Lu (D) ${ }^{7}$, Bryan D. McCloskey ${ }^{1,3}$, Wanli Yang (i) ${ }^{2}$ \& Wei Tong $^{1}$

Recent research has explored combining conventional transition-metal redox with anionic lattice oxygen redox as a new and exciting direction to search for high-capacity lithium-ion cathodes. Here, we probe the poorly understood electrochemical activity of anionic oxygen from a material perspective by elucidating the effect of the transition metal on oxygen redox activity. We study two lithium-rich layered oxides, specifically lithium nickel metal oxides where metal is either manganese or ruthenium, which possess a similar structure and discharge characteristics, but exhibit distinctly different charge profiles. By combining X-ray spectroscopy with operando differential electrochemical mass spectrometry, we reveal completely different oxygen redox activity in each material, likely resulting from the different interaction between the lattice oxygen and transition metals. This work provides additional insights into the complex mechanism of oxygen redox and development of advanced highcapacity lithium-ion cathodes.

\footnotetext{
${ }^{1}$ Energy Storage and Distributed Resources Division Lawrence Berkeley National Laboratory Berkeley, CA 94720, USA. ${ }^{2}$ Advanced Light Source Lawrence Berkeley National Laboratory Berkeley, CA 94720, USA. ${ }^{3}$ Department of Chemical and Biomolecular Engineering, University of California, Berkeley, CA 94720, USA. ${ }^{4}$ X-ray Sciences Division, Argonne National Laboratory, Argonne, IL 60439, USA. ${ }^{5}$ Center for Functional Nanomaterials Brookhaven National Laboratory Upton, NY 11973, USA. ${ }^{6}$ Stanford Synchrotron Radiation Lightsource SLAC National Accelerator Laboratory Menlo Park, CA 94025, USA.

${ }^{7}$ Chemical Sciences and Engineering Division Argonne National Laboratory Argonne, IL 60439, USA. Correspondence and requests for materials should be addressed to B.D.M. (email: bmcclosk@berkeley.edu) or to W.Y. (email: wlyang@lbl.gov) or to W.T. (email: weitong@lbl.gov)
} 
echargeable Li-ion battery technology has become the dominant power source for portable electronics, and is now on the verge of enabling widespread electric vehicle (EV) adoption. ${ }^{1-4}$ Nowadays, tremendous research efforts are being devoted to pushing the practical capacity of layered lithium transition-metal oxides, $\mathrm{LiTMO}_{2}(\mathrm{TM}=\mathrm{Ni}, \mathrm{Mn}, \mathrm{Co}, \mathrm{Al})$, close to their theoretical values. ${ }^{5-7}$ Meanwhile, a reversible capacity approaching $300 \mathrm{mAh} \mathrm{g}^{-1}$ was demonstrated by a modified version of a traditional layered oxide ${ }^{8}$, often reported by a formula of $\mathrm{xLi}_{2} \mathrm{MnO}_{3} \cdot(1-\mathrm{x}) \mathrm{Li}(\mathrm{Mn}, \mathrm{Ni}, \mathrm{Co}) \mathrm{O}_{2}{ }^{9-11}$ or $\mathrm{Li}_{1+\mathrm{x}}(\mathrm{Mn}, \mathrm{Ni}, \mathrm{Co})_{1-}$ ${ }_{x} \mathrm{O}_{2}{ }^{12-15}$.

This family of Li-rich layered oxides always demonstrates an exceptionally higher capacity (typically $>250 \mathrm{mAh} \mathrm{g}^{-1}$ ) than traditional stoichiometric layered oxides (e.g., $<190 \mathrm{mAh} \mathrm{g}^{-1}$ for $\left.\mathrm{LiCoO}_{2}\right) \cdot{ }^{16-22}$ Such a high capacity is far beyond the theoretical capacity originating solely from $\mathrm{Ni}$ and Co redox (i.e., $127 \mathrm{mAh}$ $\mathrm{g}^{-1}$ for $\mathrm{Ni}$ redox in $\mathrm{Li}_{1.2} \mathrm{Ni}_{0.2} \mathrm{Mn}_{0.6} \mathrm{O}_{2}$ ). Lattice oxygen is typically believed to compensate additional charge beyond TM redox upon the simultaneous removal of $\mathrm{Li}^{+}$. However, various mechanisms have been proposed regarding the precise nature of lattice oxygen participation in the active material electrochemistry. For example, $\mathrm{O}_{2}$ and/or $\mathrm{CO}_{2}$ gas evolution is known to occur in combination with oxygen vacancies at the particle surface. ${ }^{16,23-25}$ Meanwhile, $\mathrm{Mn}^{4+}$ reduction to $\mathrm{Mn}^{3+}$ induced by electrode-electrolyte reactions and/or oxygen removal, ${ }^{18}, 26-28$ electrochemical reduction of $\mathrm{O}_{2}$ molecules generated on the initial charge ${ }^{29}$, and reaction of the organic electrolyte with $\mathrm{Li}_{2} \mathrm{O}$ formed during the extended high-voltage plateau ${ }^{30}$ were proposed to occur during subsequent electrochemical cycling. ${ }^{31}$ Recently, Koga et al. described two separate mechanisms for lattice oxygen participation during electrochemical cycling: irreversible oxygen loss at the surface and reversible redox of lattice oxygen within the bulk. ${ }^{31,32}$

These studies raised significant interest in further verifying the reversible anionic oxygen redox because materials in which it is active could provide substantially higher capacity than conventional layered oxides. ${ }^{33-38}$ Extra capacity has been demonstrated in a series of $\mathrm{Li}_{2} \mathrm{TMO}_{3}$ compounds, particularly with $4 d$ and $5 d$ transition metals, in which the strong TM-O hybridization was believed to promote the reversible oxygen redox, i.e., $\mathrm{O}^{2-} \rightarrow \mathrm{O}_{2}{ }^{\mathrm{n}-}$ $(n=1,2$, or 3$) .{ }^{39-44}$ More specifically, formation of localized electron holes on oxygen that is coordinated by $\mathrm{Mn}$ and $\mathrm{Li}$ was proposed to occur upon $\mathrm{Li}$ removal in $\mathrm{Li}$-, $\mathrm{Mn}$-rich layered oxides. ${ }^{45}, 46$ Computational studies revealed the specific $\mathrm{Li}-\mathrm{O}-\mathrm{Li}$ configuration in Li-excess metal oxides holds the key to activate anionic oxygen redox by enabling the labile oxygen electrons. ${ }^{47}$ The above mentioned models consider different transition metals (i.e., $3 d, 4 d$, and $5 d$ ) that have different preference for TM-O hybridization might make the complex anionic oxygen redox even more elusive. Fundamental understanding of anionic oxygen redox is of critical importance to propose effective material design strategy to develop novel materials that harness active oxygen redox.

In this work, we aim to probe the electrochemical activity of anionic oxygen in Li-rich layered oxides by focusing on the effect of transition-metal species, $\mathrm{Mn}$ and $\mathrm{Ru}$, representing $3 d$ and $4 d$ $\mathrm{TM}$, on the oxygen redox process. Both Li-rich layered oxides, $\mathrm{Li}_{1.2} \mathrm{Ni}_{0.2} \mathrm{TM}_{0.6} \mathrm{O}_{2} \quad(\mathrm{TM}=\mathrm{Mn}, \mathrm{Ru})$, possess a similar crystal structure and enable a similar amount of Li removal and uptake during the charge-discharge process, but with significantly different charge profiles characterized by the existence of a voltage plateau at $4.55 \mathrm{~V}$ in the Mn-based material, but not the Ru-based one. Here, we perform a comprehensive study to capture the oxygen activity, which could range from $\mathrm{O}^{2-}$ in the crystal lattice to $\mathrm{O}^{0}$ in the extreme case of $\mathrm{O}_{2}$ gassing, by combining a suite of soft X-ray spectroscopy techniques with in situ differential electrochemical spectrometry (DEMS). We observe completely different oxygen behavior in the two materials, the sharp contrast between them providing strong experimental evidence for a particularly large reversible anionic oxygen redox observed in the Mn-based material, but not the Ru-based one. We believe these findings will provide additional insights into the complex oxygen redox mechanism and development of advanced high-capacity Li-ion cathodes. Moreover, this work demonstrates an explicit example of the employment of resonant inelastic X-ray scattering (RIXS) technique in understanding solid-state oxygen redox processes for energy storage and conversion applications.

\section{Results}

Structural characterization of pristine $\mathrm{Li}_{1.2} \mathrm{Ni}_{\mathbf{0 . 2}} \mathrm{Mn}_{\mathbf{0 . 6}} \mathrm{O}_{2}$ and $\mathbf{L i}_{1.2} \mathbf{N i}_{\mathbf{0 . 2}} \mathbf{R u}_{\mathbf{0 . 6}} \mathbf{O}_{\mathbf{2}}$. The two compounds, $\mathrm{Li}_{1.2} \mathrm{Ni}_{0.2} \mathrm{Mn}_{0.6} \mathrm{O}_{2}$ and $\mathrm{Li}_{1.2} \mathrm{Ni}_{0.2} \mathrm{Ru}_{0.6} \mathrm{O}_{2}$, henceforth denoted as LNMO and LNRO, respectively, were synthesized by conventional solid-state reaction method. Both LNMO and LNRO exhibit similar X-ray diffraction (XRD) patterns (Fig. 1a). Most of the characteristic XRD peaks can be indexed based on $R \overline{3} m$ symmetry $\left(\alpha-\mathrm{NaFeO}_{2}\right)$, except those in the $2 \theta$ region of 5 to $8^{\circ}$, corresponding to 19 and $31^{\circ}$ $\left(\mathrm{CuK}_{\alpha}\right.$ radiation, $1.5406 \AA$ А $)$. These extra peaks are typically assigned to the superstructure peaks originating from $\mathrm{Li}$ and $\mathrm{TM}$ cation ordering on the TM layer in monoclinic $\mathrm{Li}_{2} \mathrm{TMO}_{3}(\mathrm{TM}=$ $\mathrm{Mn}, \mathrm{Ru}$ ), being more clearly observed if its chemical formula is rewritten as $\mathrm{Li}\left[\mathrm{Li}_{1 / 3} \mathrm{TM}_{2 / 3}\right] \mathrm{O}_{2}$. As such, the monoclinic phase, $\mathrm{Li}_{2} \mathrm{MnO}_{3}$, belongs to $C 2 / m$ space group, while, $\mathrm{Li}_{2} \mathrm{RuO}_{3}$ was reported to be either $C 2 / c$ or $P 21 / m .{ }^{48}, 49$ Such structural distortion could be resulted by a small lattice energy difference. To further confirm the similar crystal structure between LNMO and LNRO, high-resolution synchrotron XRD patterns were refined by the conventional Rietveld method (Fig. 1b, c). Our refinements were performed based on $R \overline{3} m$ and $C 2 / m, C 2 / c$ for LNMO, LNRO, respectively. A good fit was obtained for LNMO for both $C 2 / m$ (Fig. 1b) and $R \frac{}{3} m$ (Supplementary Fig. 1a). For LNRO refinement, $C 2 / c$ symmetry gave a better fit (Fig. 1c) than $R \overline{3} m$ symmetry (Supplementary Fig. 1b). The refined structural parameters of LNMO and LNRO are given in Supplementary Table 1, 2 , respectively. Rietveld refinement results suggest the asproduced LNMO and LNRO samples fit the structural model of monoclinic solid solution, though the nanocomposite concept concerning the mixture of layered $\mathrm{LiNiO}_{2}(R \overline{3} \mathrm{~m})$ and monoclinic $\mathrm{Li}_{2} \mathrm{RuO}_{3}(C 2 / c)$ cannot be excluded.

Scanning electron microscopy (SEM) and high-resolution transmission electron microscopy (HRTEM) were used to further verify the morphology and crystal structure. Overall, both exhibited a similar morphology, composed of agglomerated primary particles, as observed in SEM images (Fig. 1d, h). A number of particles were examined using HRTEM and representative images are shown in Fig. 1e-g, i-k. The LNMO sample has a slightly smaller primary particle size than the LNRO sample, both being a few hundred nanometers. They both exhibit a well-defined layered structure with a thin layer $(\sim 1.5 \mathrm{~nm})$ of spinel and/or rocksalt phase on the surface. Both electron diffraction (ED) patterns and fast Fourier transformation results along the [001] and [301] zone axis of $C 2 / m$ and $C 2 / c$ from LNMO and LNRO particle showed high structural consistency. In contrast, an ED pattern from a LNRO particle is inconsistent with that simulated based on $P 21 / m$ symmetry, confirming that our LNRO sample belongs to $C 2 / c$ space group. Therefore, a similar crystal structure and morphology between the two samples was confirmed using combined synchrotron XRD, TEM, and SEM techniques.

First charge-discharge characteristics of LNMO and LNRO. The first cycle voltage profiles are shown in Fig. 2a, b. The as- 
produced LNRO sample demonstrated an electrochemical activity, characterized by a charge capacity of $239 \mathrm{mAh} \mathrm{g}^{-1}$ and a discharge capacity of $213 \mathrm{mAh} \mathrm{g}^{-1}$, leading to a coulombic efficiency of $88.9 \%$. In comparison, LNMO sample exhibited a charge capacity of $310 \mathrm{mAh} \mathrm{g}^{-1}$ and a discharge capacity of 232 $\mathrm{mAh} \mathrm{g}^{-1}$ with a coulombic efficiency of $75.0 \%$. With respect to the theoretical capacity of $238 \mathrm{mAh} \mathrm{g}^{-1}$ and $318 \mathrm{mAh} \mathrm{g}^{-1}$ based on $1 \mathrm{Li}^{+}$for LNRO and LNMO, this corresponds to $1.01 \mathrm{Li}^{+}$ removal/0.89 $\mathrm{Li}^{+}$uptake for LNRO and $0.97 / 0.73 \mathrm{Li}^{+}$for $\mathrm{LNMO}$, respectively. From this perspective, a common feature of about 1 $\mathrm{Li}^{+}$removal during the charge was revealed for both compounds. Of note, the last $0.2 \mathrm{Li}$ was not removed from both compounds in this study, additional studies regarding the reversible extraction of the final $0.2 \mathrm{Li}$ are needed to understand the origin of this limitation (outside the scope of this study).

Despite this similarity, these two compounds exhibited noticeably different charge characteristics. Similar to other reported $\mathrm{Li}, \mathrm{Mn}$-rich layered oxides, LNMO exhibited a long plateau at $4.55 \mathrm{~V}$ in the high-voltage region, often referred to as the electrochemical activation process. In contrast, no obvious voltage plateau was observed for LNRO, instead, the charge profile of LNRO was a sloping curve with most of the capacity extracted below $4.5 \mathrm{~V}$. This difference was even more pronounced in the differential capacity $(\mathrm{d} Q / \mathrm{d} V)$ plots (Fig. 2c). The charge profile of LNMO was characterized by a strong anodic peak at $4.55 \mathrm{~V}$, corresponding to the extended voltage plateau, as well as two weak anodic peaks around 3.8 and $4.1 \mathrm{~V}$. In comparison, the strong anodic peak in the high-voltage region was absent in the charge profile of LNRO (Fig. 2d), and instead, a relatively strong peak at $3.65 \mathrm{~V}$ was observed along with two minor peaks at 3.75 and $4.1 \mathrm{~V}$. The corresponding cathodic peaks, which were clearly visible in the LNRO, unlike the LNMO, were located around 3.7 and $3.4 \mathrm{~V}$. By comparing these features to the $\mathrm{Li}_{2} \mathrm{RuO}_{3}$ base compounds $39,40,44,50,51$, it is likely that the oxidation/reduction couple around 3.65/3.4 V is related to Ru redox, but the shape of the curves suggests that $\mathrm{Ni2}+$ and $\mathrm{Ru} 4+$ oxidation might be superimposed.

The structural and electrochemical characterization of LNMO and LNRO compounds reveal three interesting observations: (1) the compounds possess a similar crystal structure, (2) they allow a similar amount of Li removal on the initial charge, but (3) they have remarkably different charge profiles (voltage plateau at 4.55 $\mathrm{V}$ for LNMO vs. a sloping profile in LNRO). Given these unique features, LNMO and LNRO might be suitable model compounds a

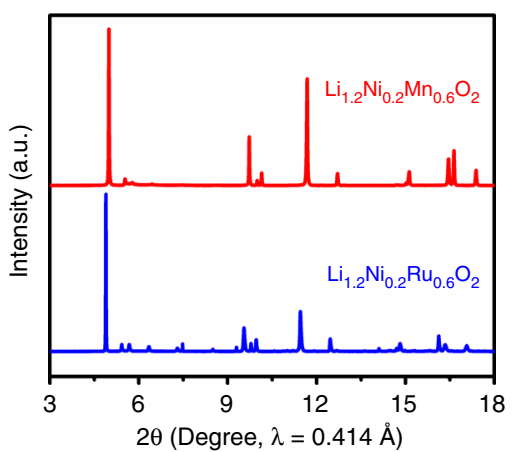

b

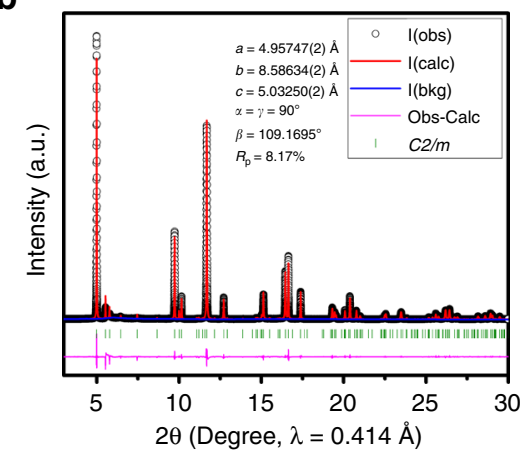

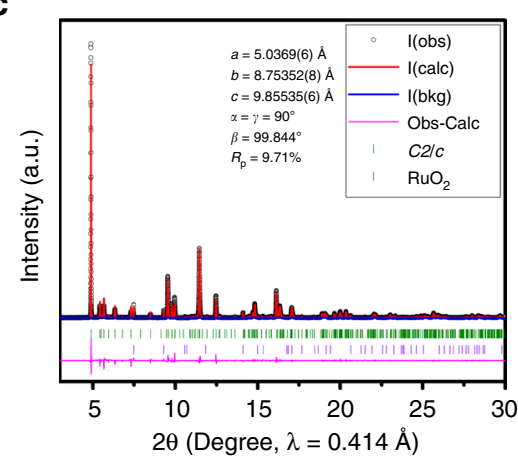

d

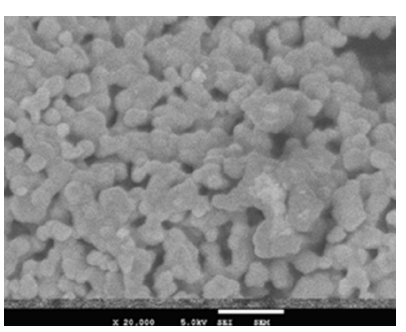

f

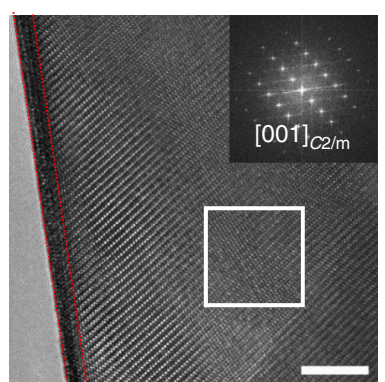

e

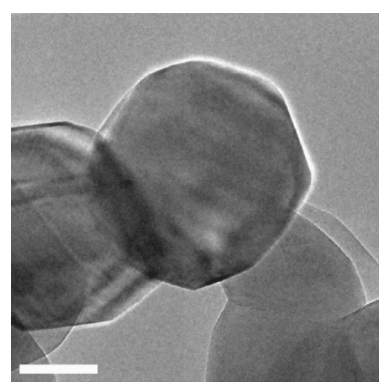

9

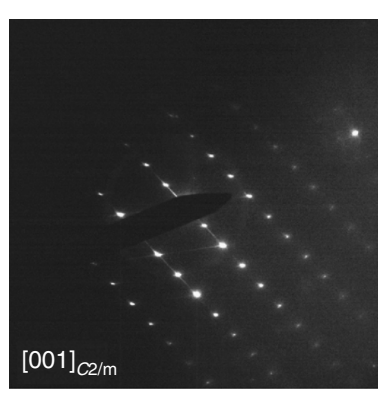

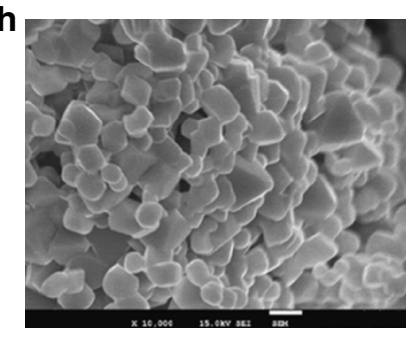

j
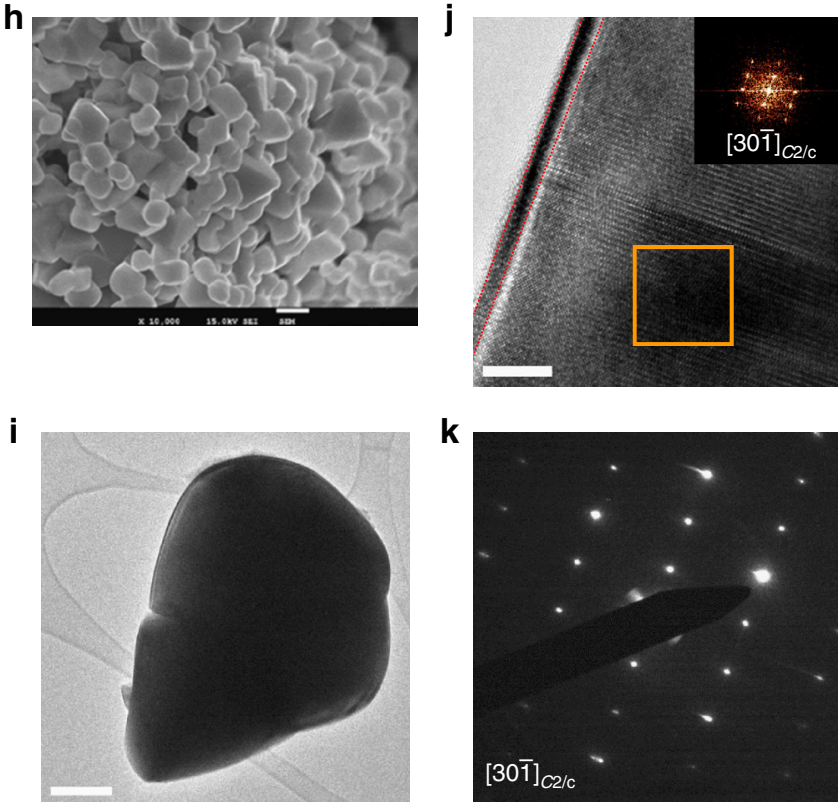

$\mathbf{k}$

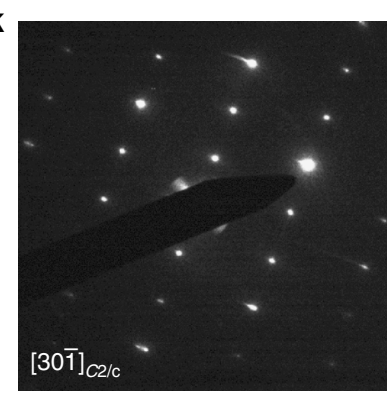

Fig. 1 Structural characterization of pristine $\mathrm{Li}_{1.2} \mathrm{Ni}_{0.2} \mathrm{Mn}_{0.6} \mathrm{O}_{2}(\mathrm{LNMO})$ and $\mathrm{Li}_{1.2} \mathrm{Ni}_{0.2} \mathrm{Ru}_{0.6} \mathrm{O}_{2}(\mathrm{LNRO})$. a Synchrotron XRD patterns, showing a similar crystal structure between these two compounds; XRD Rietveld refinement of $\mathbf{b} L \mathrm{LNMO}$ based on monoclinic $\mathrm{C} 2 / \mathrm{m}$ and $\mathbf{c} \mathrm{LNRO}$ based on monoclinic $\mathrm{C} 2 / \mathrm{c}$; $\mathbf{d}$ scanning electron microscopy (SEM) image of LNMO, the scale bar is $1 \mu \mathrm{m} ; \mathbf{e}$, $\mathbf{f}$ high-resolution transmission electron microscopy (HRTEM) images of LNMO with fast Fourier transform (FTT) of the selected area, the scale bar in (e) and (f) is 50 and $5 \mathrm{~nm}$, respectively; $\mathbf{g}$ electron diffraction (ED) pattern for LNMO; $\mathbf{h}$ SEM image of LNRO, the scale bar is $1 \mu \mathrm{m} ; \mathbf{i}, \mathbf{j}$ HRTEM images of LNRO with FTT of the selected area, the scale bar in (i) and (j) is 100 and $2 \mathrm{~nm}$, respectively; $\mathbf{k}$ ED pattern for $L N R O$ 
a

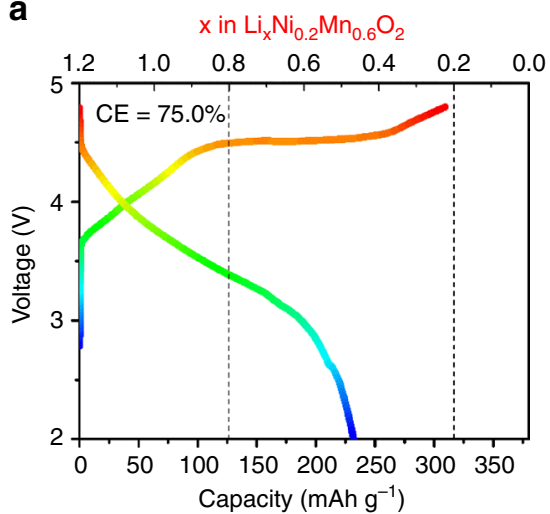

C

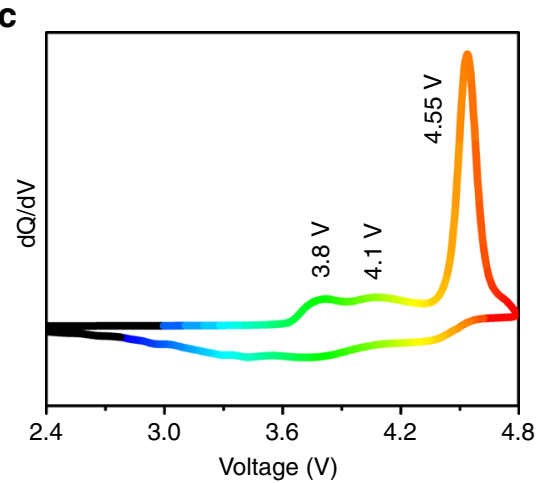

b

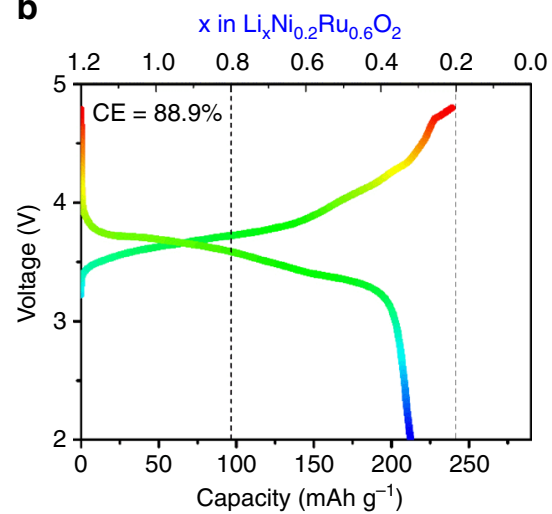

d

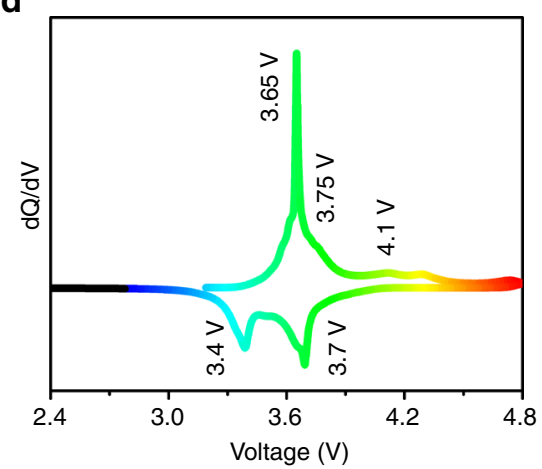

Fig. 2 First charge-discharge characteristics of LNMO and LNRO. The first cycle voltage profile of a LNMO and $\mathbf{b} L N R O$; differential capacity (dQ/dV) plot of $\mathbf{c} L N M O$ and $\mathbf{d}$ LNRO. Cells were cycled between 4.8 and $2.0 \mathrm{~V}$ at a current density of $5 \mathrm{~mA} \mathrm{~g}^{-1}$ at room temperature
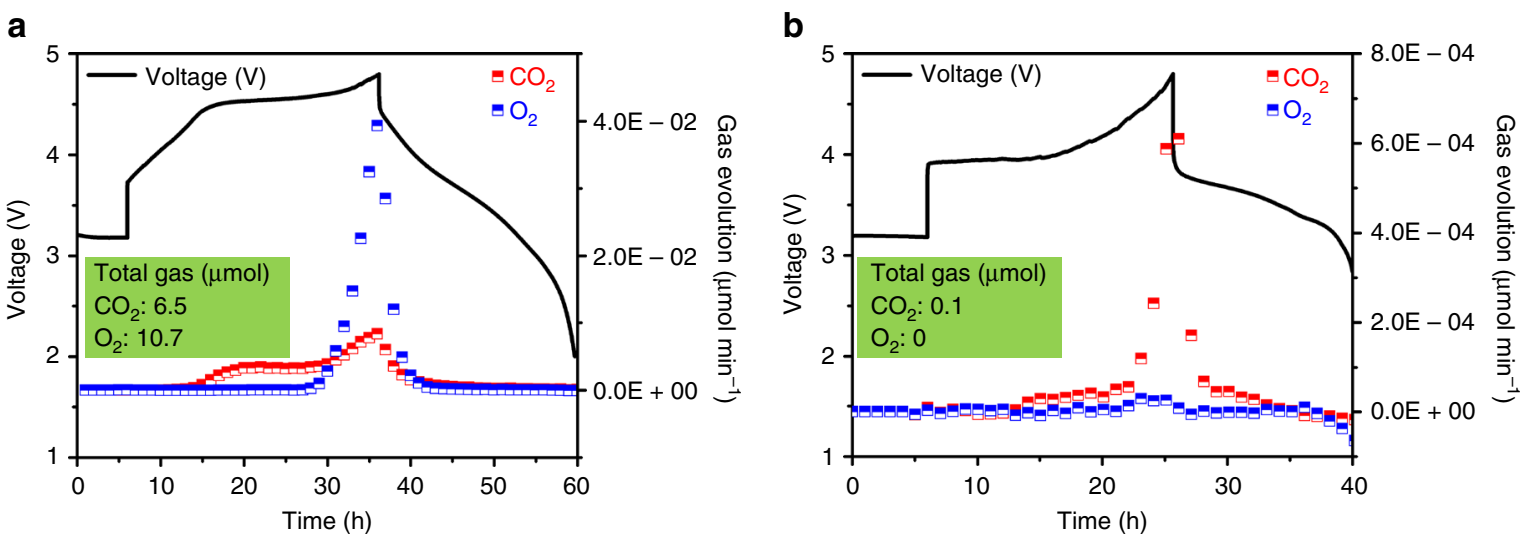

Fig. 3 Gas evolution of LNMO and LNRO by operando DEMS. The first cycle voltage profiles and gas evolution rates of $\mathbf{a} L N M O$ and $\mathbf{b} L N R O$. The total active cathode material used for the measurement was $32.9 \mathrm{mg}$ LNMO $(387 \mu \mathrm{mol})$ and $28.6 \mathrm{mg}$ LNRO $(253 \mu \mathrm{mol})$. Cells were cycled between 4.8 and 2.0 $\mathrm{V}$, at a current of $10 \mathrm{mAg}^{-1}$

to investigate the underlying oxygen activation mechanisms in the high-voltage region.

Gas evolution of LNMO and LNRO by operando DEMS. We first used operando DEMS to monitor any oxygen evolution stemming from the $2 \mathrm{O}^{2-} \rightarrow \mathrm{O}_{2}{ }^{0}+4 \mathrm{e}^{-}$compensation reaction and quantify the irreversible loss of lattice oxygen as gaseous products, thus probe the extent of irreversibility of any oxygen participation in the charging process. The operando DEMS results (Fig. 3) were collected at a current density of $10 \mathrm{~mA} \mathrm{~g}^{-1}$ with an electrode loading of $\sim 30 \mathrm{mg} \mathrm{cm}^{-2}$. The higher loading and larger current density accounted for a larger overpotential observed at the beginning of charge for LNRO and LNMO. The polarization was particularly pronounced for LNRO because of its relatively large particle size. Trace amounts $(<0.1 \mathrm{nmol}$ $\min ^{-1}$ ) of $\mathrm{H}_{2}, \mathrm{C}_{2} \mathrm{H}_{4}, \mathrm{CH}_{4}$, and $\mathrm{CO}$ were detected at the beginning of charging, but are not shown here for clarity. The LNMO electrode tested in the operando DEMS cell demonstrated a charge capacity of $302 \mathrm{mAh} \mathrm{g}^{-1}$ and a discharge capacity of 234 $\mathrm{mAh} \mathrm{g}^{-1}$, consistent with those obtained in our regular electrochemical cells. For LNMO (Fig. 3a), $\mathrm{CO}_{2}$ began to evolve at $4.0 \mathrm{~V}$, the evolution rate moderately increasing with potential and reaching a maximum at $4.8 \mathrm{~V}$. Exhibiting drastically different behavior, $\mathrm{O}_{2}$ evolution was not detected until $4.5 \mathrm{~V}$, the $\mathrm{O}_{2}$ evolution rate dramatically increasing with potential, reaching a rate of $\sim 410^{-2} \mu \mathrm{mol} \mathrm{m^{-1 }}$ at $4.8 \mathrm{~V}$. The cumulative 
a

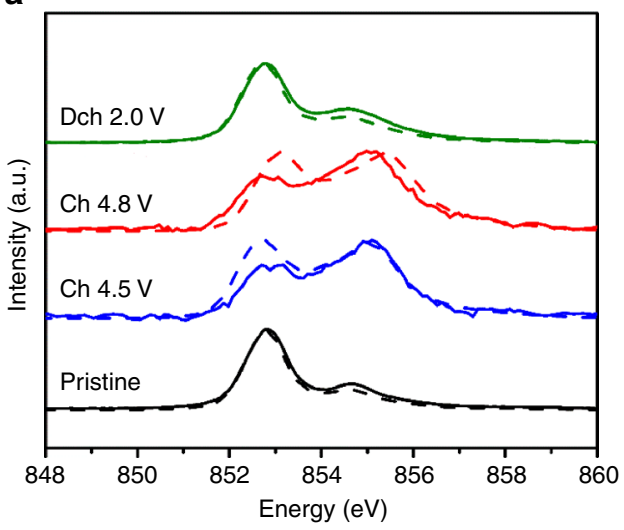

C

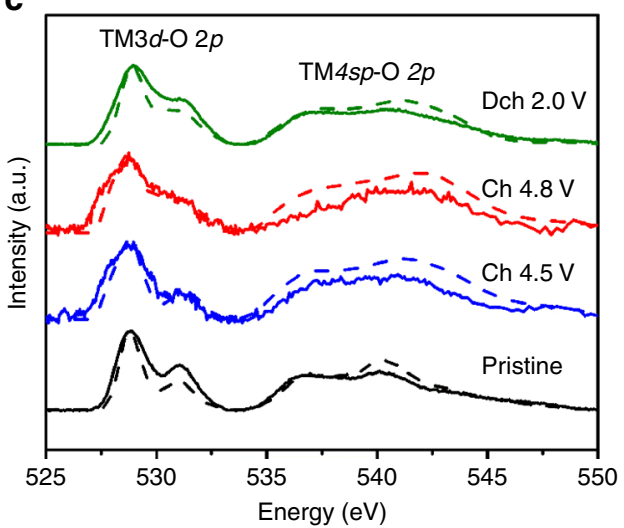

b

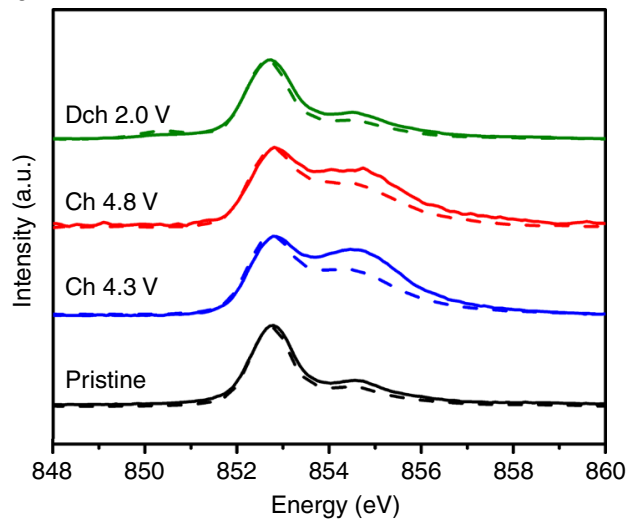

d

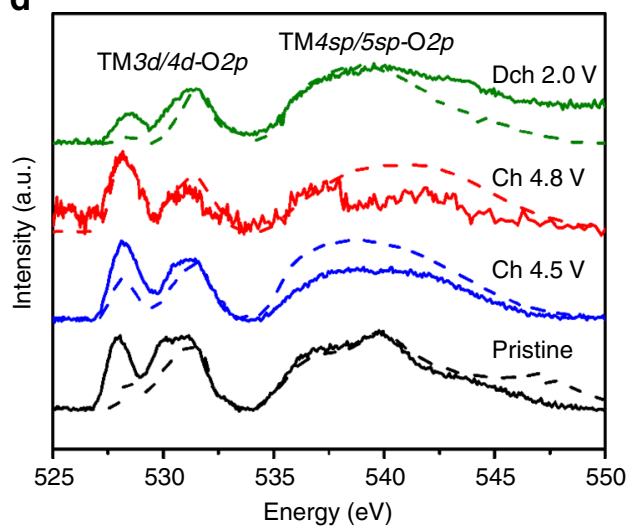

Fig. 4 Electronic structures of $\mathrm{Ni}$ and $\mathrm{O}$ as probed by sXAS. sXAS Ni L3-edge spectra of a LNMO and $\mathbf{b}$ LNRO electrodes; sXAS O K-edge spectra of $\mathbf{c}$ LNMO and $\mathbf{d}$ LNRO electrodes in FY and TEY modes at different states of charge. Solid and dash line indicate FY and TEY mode, respectively

$\mathrm{CO}_{2}$ and $\mathrm{O}_{2}$ detected from LNMO during the first cycle was 6.5 and $10.7 \mu \mathrm{mol}$, respectively.

If we assume $\mathrm{O}_{2}$ evolution originates solely from the active electrode (rather than electrolyte decomposition), $10.7 \mu \mathrm{mol}$ total $\mathrm{O}_{2}$ evolution corresponds to $2.8 \%$ of the lattice oxygen in LNMO (32.9 mg, equivalent to $387 \mu \mathrm{mol}$ ). Taking $4 \mathrm{e}^{-} / \mathrm{O}_{2}$, as would be expected for $\mathrm{O}_{2}$ release from lattice oxygen, the total irreversible capacity associated with this oxygen loss is $35 \mathrm{mAh} \mathrm{g}^{-1}$, which can account for slightly less than half of the total irreversible capacity $\left(78 \mathrm{mAh} \mathrm{g}^{-1}\right)$ on the first charge. Electrolyte (EC/DEC) is electrochemically stable until $\sim 4.8 \mathrm{~V}$ with a blank electrode composed of conductive carbon and PVDF. ${ }^{52,53}$ We do not attempt to ascribe a capacity to the $\mathrm{CO}_{2}$ evolution, as $\mathrm{CO}_{2}$ is likely evolved from surface $\mathrm{Li}_{2} \mathrm{CO}_{3}$ that remains after synthesis. Of note, any non-volatile electrolyte decomposition products that cannot be detected using DEMS could contribute to the irreversible capacity on charge. The gas evolved during the second cycle was composed of $0.9 \mu \mathrm{mol} \mathrm{CO}_{2}$ with no detectable $\mathrm{O}_{2}$.

In stark contrast to the substantial gas evolution from LNMO, LNRO evolved a minimal amount of $\mathrm{CO}_{2}$ and almost no $\mathrm{O}_{2}$ (Fig. 3b). Note that the LNRO gas evolution is plotted on a different scale than that of LNMO for clarity. For LNRO, no appreciable $\mathrm{O}_{2}$ evolution was detected in the charging process, with the evolution rate remaining below $10^{-2} \mathrm{nmol} \mathrm{min}^{-1}$, even at $4.8 \mathrm{~V}$. Similar to $\mathrm{LNMO}, \mathrm{CO}_{2}$ gas evolution began at $4.0 \mathrm{~V}$ and increased with charge potential, however, the rate of $\mathrm{CO}_{2}$ evolution was considerably less in LNRO, with only $0.1 \mu \mathrm{mol}$ total $\mathrm{CO}_{2}$ evolved in the entire first cycle. This implies less residual surface carbonate and/or a different reactivity of LNRO with the carbonate electrolyte, likely due to its slightly large particle size compared to LNMO. In contrast to LNMO, with no $\mathrm{O}_{2}$ detected from LNRO, we do not ascribe any irreversible charge capacity to oxygen participation via oxygen loss.

The operando DEMS measurements revealed completely different outgassing behaviors in LNMO and LNRO, when they were cycled under identical conditions. Even when LNRO was charged to a higher potential $(5.0 \mathrm{~V})$, no $\mathrm{O}_{2}$, but a moderate increase in $\mathrm{CO}_{2}$ evolution $(0.6 \mu \mathrm{mol})$ was detected, which was significantly lower compared to the total gas evolution from LNMO (Supplementary Fig. 2). Such drastic differences indicate these two compounds might exhibit significantly different oxygen activity in the solid-state as well. Therefore, we probed the electronic structures of transition metals and oxygen using elemental sensitive X-ray spectroscopy techniques to study the electrochemical redox change during the electrochemical reaction.

Electronic structures of $\mathrm{Ni}$ and $\mathrm{O}$ as probed by sXAS. Soft X-ray absorption spectroscopy (sXAS) naturally provides elemental and orbital sensitivity to the redox states in battery electrodes with varied depth sensitivities. ${ }^{54}$ Due to the different mean free path of electrons and photons, total electron yield (TEY) and fluorescence yield (FY) modes yield chemical information at a depth of $10 \mathrm{~nm}$ and $\sim 100 \mathrm{~nm}$ from the particle surface, respectively. As shown in Fig. $4 \mathrm{a}, \mathrm{b}, \mathrm{Ni}$ L3-edge at $852-856 \mathrm{eV}$ exhibits splitting features at high and low energy. The strong Ni L3-edge feature at $852.9 \mathrm{eV}$ is from $\mathrm{Ni}^{2+}, 855.1 \mathrm{eV}^{2}$ from $\mathrm{Ni}^{4+}$, while $\mathrm{Ni}^{3+}$ is located at a slightly lower energy range with multiple features. ${ }^{54,55}$ It is clearly shown that $\mathrm{Ni}$ is in its $2+$ oxidation state in both pristine LNMO and LNRO. Upon charging, the general increase in Ni L3-edge peak in the high-energy range suggests $\mathrm{Ni}$ oxidation. The strong $855.1 \mathrm{eV}$ 
a

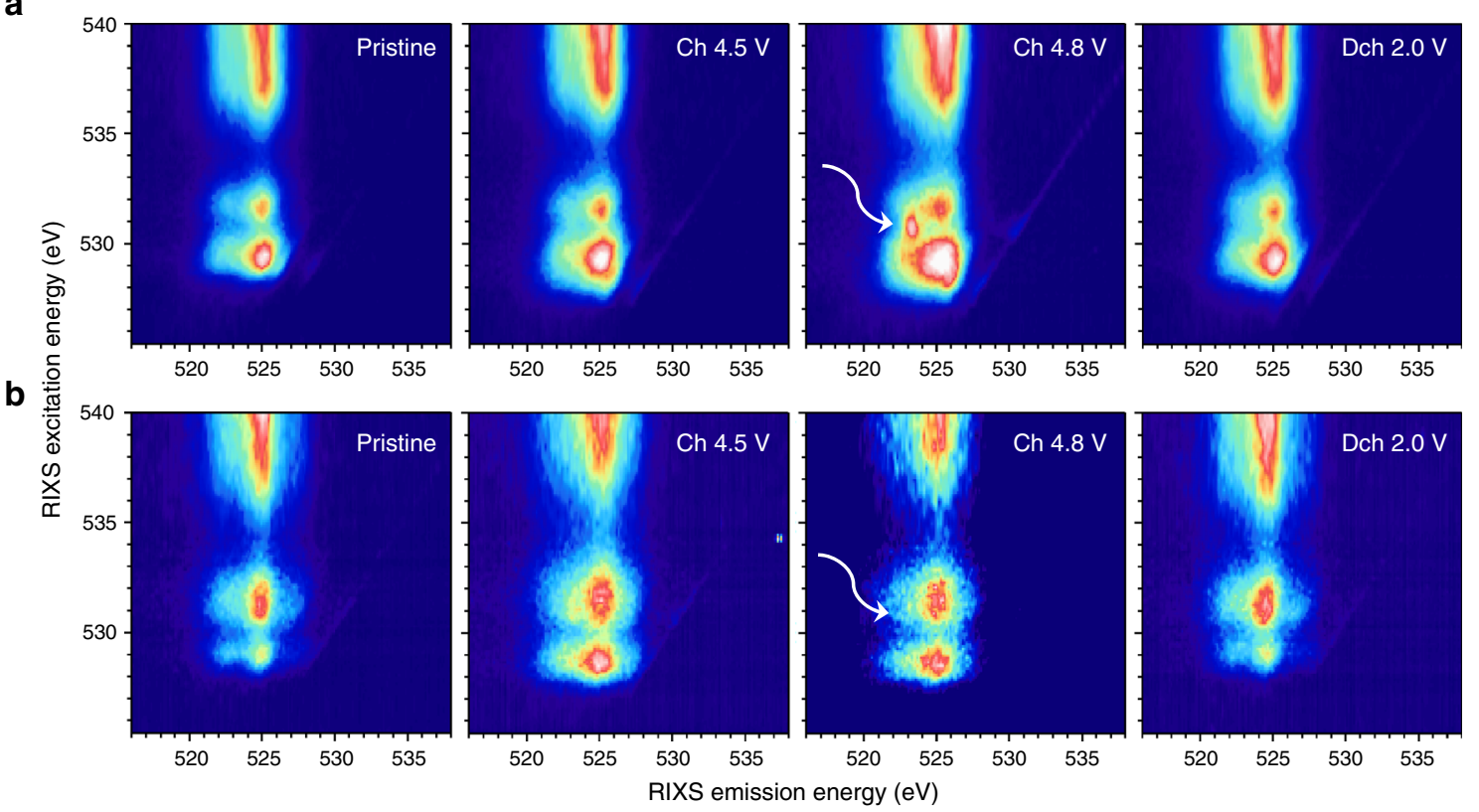

Fig. 5 Electronic structures of O as probed by RIXS. O K-edge RIXS maps of $\mathbf{a}$ LNMO and $\mathbf{b}$ LNRO electrodes at different states of charge. The while arrow points to the specific oxygen redox state that is absent in LNRO

peak of the charged LNMO at $4.5 \mathrm{~V}$ suggests $\mathrm{Ni}^{4+}$ state, while the relatively broad shoulder feature of the charged LNRO indicates a mixed valence of $\mathrm{Ni}^{3+}$ and $\mathrm{Ni}^{4+}$. Further increasing charging voltage to $4.8 \mathrm{~V}$ did not lead to an obvious change in Ni oxidation state, suggesting the completion of $\mathrm{Ni}$ redox by $4.5 \mathrm{~V}$ and $4.3 \mathrm{~V}$ for LNMO and LNRO, respectively. The Ni valence state reverts back to its divalent state after the first discharge, as the discharged material spectra are similar to those of the pristine material. Comparison between FY and TEY mode for both compounds revealed a slight $\mathrm{Ni}$ reduction at the surface of the charged electrodes, as evidenced by a slight decrease in the relative intensity of the TEY Ni L3-edge feature compared to the analogous FY spectra at high energy. No major change in Mn L3-edge (Supplementary Fig. 3a) was detected, but a small reduction after discharge was revealed.

Variation in transition-metal redox during the electrochemical reaction is inextricably linked to the hybridization between $\mathrm{TM} 3 d / 4 d$ and $\mathrm{O} 2 p$ orbitals. In an attempt to examine the electronic states of $\mathrm{O}$ at various charging states, we collected $\mathrm{O} \mathrm{K}$ edge sXAS spectra (Fig. 4c, d), which are characterized by the preedge peaks between 525 and $535 \mathrm{eV}$ and a broad peak above 535 $\mathrm{eV}$, corresponding to the hybridization of $\mathrm{TM} 3 d / 4 d-\mathrm{O} 2 p$ and TM4sp/5sp-O2p, respectively. The pre-edge features can be further distinguished by two peaks, characterizing the excitation from the $\mathrm{O} 2 p$ orbital to unoccupied $t_{2 g}(<530 \mathrm{eV})$ and $e_{g}$ orbitals $(>530 \mathrm{eV})$ of the TM, accordingly. The new low-energy shoulder at $527.8 \mathrm{eV}$ in the spectra of $4.5,4.8 \mathrm{~V}$ charged LNMO is from the $\mathrm{Ni}^{4+}$ state. $^{55,56}$ Estimates of the average electron hole distribution and effective charge on oxygen anions have been gleaned by measuring the absorption intensity of sXAS. ${ }^{26}, 45,46,57,58$ However, it is difficult to differentiate TM-O hybridization from the intrinsic oxygen state because the hybridization peaks are overlapping with the $\mathrm{O} 2 p$ states (Supplementary Fig. 3b). Furthermore, the $\mathrm{O}-\mathrm{K}$ pre-edge intensity change upon electrochemical cycling is expected, because Li extraction often leads to more covalent nature, thus enhances the TM-O hybridization feature, regardless of oxygen redox. Indeed, such lineshape and intensity changes were observed in other battery electrodes, e.g., spinel $^{55}$ and olivine ${ }^{59}$ materials. Therefore, we decided not to discuss the oxygen redox based on O-K sXAS. The pre-edge peak above $530 \mathrm{eV}$ in sXAS O K-edge of LNRO (Fig. 4d) at the pristine and discharged states was more pronounced compared to that of LNMO, due to the different hybridization features between $\mathrm{Ru}$ $\mathrm{O}^{60}$ and $\mathrm{Mn}-\mathrm{O}^{28}$. Additionally, the difference between the pristine and discharged LNRO samples is likely due to the formation of surface species, which is often different for materials with different surface reactivity.

Electronic structures of $\mathbf{O}$ as probed by RIXS. Effective probe of the intrinsic lattice oxygen activity calls for new techniques that could provide more sensitivity to the chemical states of lattice oxygen. Therefore, we employed RIXS technique to further reveal the decay information at each sXAS excitation energy. RIXS can be considered as a "further resolved" sXAS decay process by providing detailed information on energy distribution of the fluorescence signals. ${ }^{61,62}$ The new information on the energy of the outgoing (emission) photons further resolves the electron states that are involved in the different low-energy excitations, thus providing much more sensitivity and clarification to define the chemical state of oxygen.

The RIXS intensity presented in Fig. 5 is plotted against the excitation energy ( $y$-axis, same as $x$-axis in sXAS) and emission energy ( $x$-axis). In the O K-edge maps, RIXS decay channels are dominated by fluorescence features (vertical stripes in the maps) that have fixed emission energy around $525 \mathrm{eV}$. These vertical RIXS stripes along the $525 \mathrm{eV}$ emission energy have been extensively studied in transition-metal oxides and are characteristic of the TM-O hybridization and general $\mathrm{O}^{2-}-2 \mathrm{p}$ bands. ${ }^{63}$ Consistent with sXAS spectra, the RIXS map of O K-edge is composed of a dispersed stripe feature, corresponding to TM4sp/ $5 s p-\mathrm{O} 2 p$ hybridization at excitation energies above $535 \mathrm{eV}$, and two small features at excitation energies below $535 \mathrm{eV}$, which are associated with TM3d/4d-O $2 p$ hybridization. For LNMO electrodes (Fig. 5a), one relatively large fluorescence feature was observed at an excitation energy of $\sim 529.2 \mathrm{eV}$ ( $t_{2 g}$ orbitals) along with a relatively small feature at $\sim 531.5 \mathrm{eV}$ ( $e_{g}$ orbitals) in the pristine state. Upon charge, the $529.2 \mathrm{eV}$ feature tended to grow due to its more covalent nature (corresponding to Ni oxidation), 
a

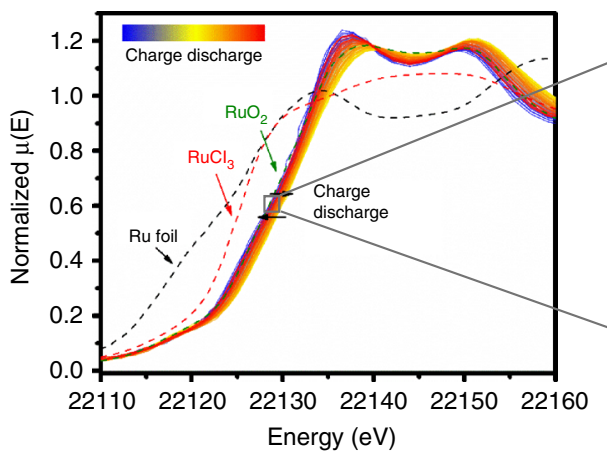

b

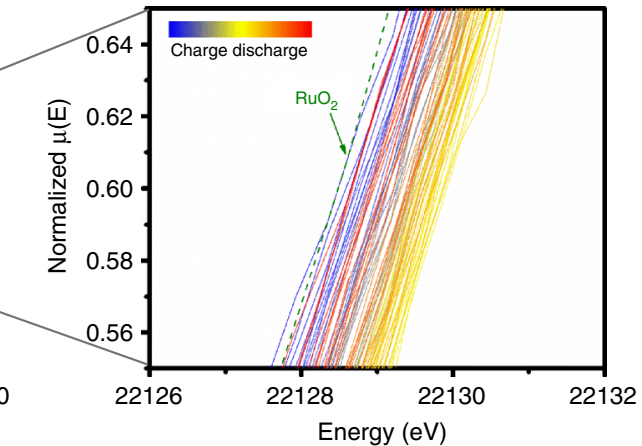

C

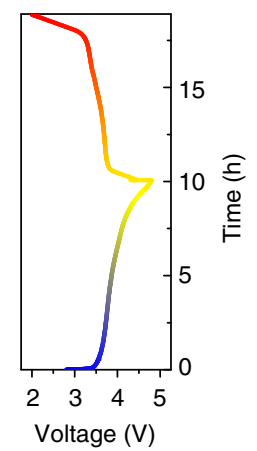

d

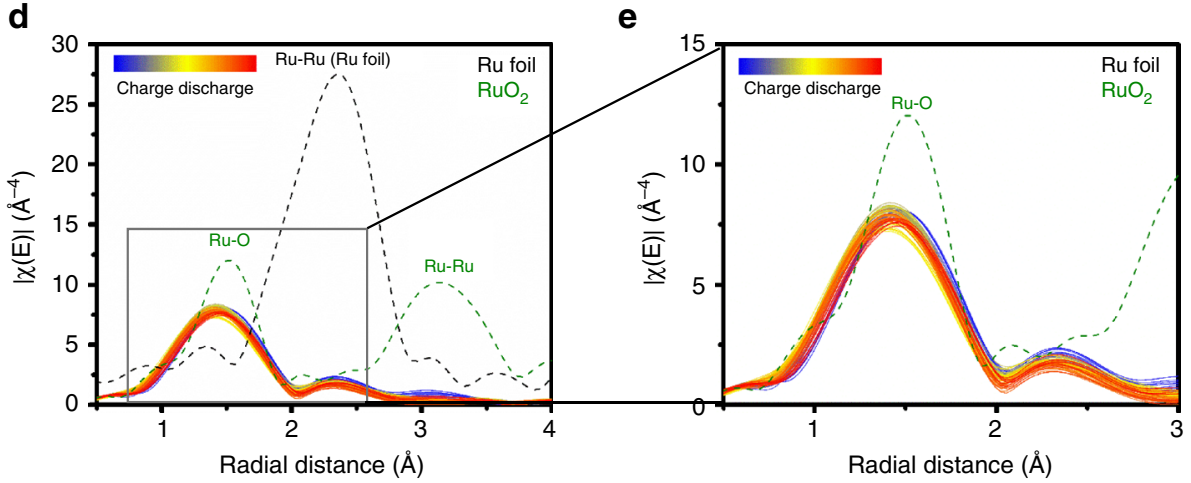

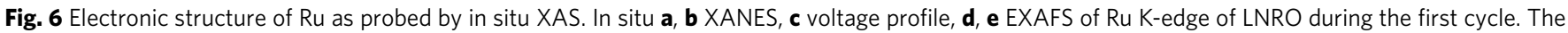
in situ cell was charged at $C / 10$ and discharged at $C / 7$

which was consistent with the enhancement of the sXAS peak below $530 \mathrm{eV}$ during charge (Fig. 4c).

When the LNMO was charged to $4.8 \mathrm{~V}$, a striking RIXS feature appears (marked by white arrow in Fig. 5a) at excitation and emission energies of 530.8 and $523.75 \mathrm{eV}$, respectively. The critical information that is clearly revealed here is the emission energy of this additional oxygen feature was lower than that of the standard fluorescence features originating from the TM-O hybridization as discussed above. More importantly, this sharp RIXS feature disappeared after $2.0 \mathrm{~V}$ discharge, indicating this feature is a unique fingerprint of the oxygen state change upon electrochemical cycling. Although the ultimate understanding of this RIXS feature requires sophisticated theoretical RIXS interpretation, which is an ongoing effort and out of the scope of this experimental report, we note that such RIXS feature has been observed in non- $\mathrm{O}^{2-}$ species, e.g., $\mathrm{O}_{2}$ gas ${ }^{64,}{ }^{65}$. The standard features in the RIXS maps of LNRO O-K edge are also along 525 $\mathrm{eV}$ emission energy, similar to those of LNMO. The different feature profile with excitation energies of 528.5 and $531.1 \mathrm{eV}$ is due to the TM-O hybridization, consistent with the lineshape difference in sXAS (Fig. 4c, d). However, in sharp contrast to that of LNMO, at $4.8 \mathrm{~V}$ charge, no striking feature was observed in LNRO (Fig. 5b). This unique striking feature that appears at $530.8 \mathrm{eV}$ excitation and $523.75 \mathrm{eV}$ emission energies is a direct evidence of the oxygen state change (oxygen redox) in the electrochemistry of LNMO. Therefore, no oxygen participates in the electrochemistry of LNRO, and hence Ru must be electrochemically active (as confirmed later).

Electronic structure of Ru as probed by in situ XAS. Due to the high excitation energy of Ru, RIXS maps of Ru L-edge were not collected. As discussed above, reversible Ru redox is anticipated to participate in the electrochemistry of LNRO because the RIXS maps of O K-edge imply that lattice oxygen is not contributing to charge compensation. To verify our hypothesis, in situ hard XAS spectra (Fig. 6) were collected on the Ru K-edge during the first cycle of LNRO. Compared to the X-ray absorption near-edge spectra (XANES) of the reference compounds, including $\mathrm{RuO}_{2}$ (4 $+), \mathrm{RuCl}_{3}(3+)$, and $\mathrm{Ru}$ metal (0), the oxidation state of $\mathrm{Ru}$ was determined to be $4+$ in pristine LNRO (Fig. 6a). Upon charging, the $\mathrm{Ru}$ edge gradually shifted from its pristine state to higher energies, indicating $\mathrm{Ru}$ was oxidized. The oxidation state of $\mathrm{Ru}$ at the end of charge was estimated to be $5+$ by measuring the energy shift at half the maximal amplitude of XANES. The energy of Ru K-edge XANES for pristine and charged state was 22126.8 and $22128.5 \mathrm{eV}$, showing an increase of $1.7 \mathrm{eV}$ in energy. Such energy shift is in accordance with that $(1.5 \mathrm{eV})$ for $\mathrm{SuRuO}_{3}$ and $\mathrm{Sr}_{2} \mathrm{GdRuO}_{6}$ as the oxidation state of octahedrally coordinated $\mathrm{Ru}$ increases from $4+$ to $5+.{ }^{66}$ Meanwhile, the Ru edge moved back to the lower energy and almost to its original valence state upon discharge.

On the other hand, extended X-ray absorption fine structure (EXAFS) shown in Fig. 6b exhibits two distinct shells around 1.4 and $2.3 \AA$, corresponding to $\mathrm{Ru}-\mathrm{O}$ and $\mathrm{Ru}-\mathrm{TM}$ interactions, respectively. The two shells shifted slightly to smaller distances as a result of $\mathrm{Ru}$ oxidation during the charge process, then reverted back to their pristine distances after discharge, indicating the reversible nature of the $\mathrm{Ru}$ redox process during LNRO cycling. In further support of the $\mathrm{Ru}$ redox reversibility, no obvious change in amplitude of the $\mathrm{Ru}-\mathrm{O}$ and $\mathrm{Ru}-\mathrm{TM}$ shells was observed, revealing no change in $\mathrm{Ru}$ coordination during the electrochemical process. In situ XAS results clearly demonstrated the electrochemical activity of $\mathrm{Ru}$ and its good reversibility during electrochemical cycling, lending support to our earlier hypothesis that lattice oxygen redox need not participate in charge compensation during Li insertion/extraction.

\section{Discussion}

We clearly showed that the replacement of $3 d \mathrm{Mn}$ by $4 d \mathrm{Ru}$ substantially influenced the charge profile, and using a variety of 
spectroscopic techniques, we confirmed that this influence is primarily related to the different redox processes occurring in each material. Our discussion mainly focuses on the potential impact of the transition metal on oxygen redox activity. As opposed to $\mathrm{Mn}$ in LNMO, $\mathrm{Ru}$ is electrochemically active in LNRO. Despite the difficulty in determining the final valence state of $\mathrm{Ru}, \mathrm{Ru}$ was indirectly verified to be at pentavalent state after charge. Given a reversible capacity of $213 \mathrm{mAh} \mathrm{g}^{-1}$ for the LNRO sample (corresponding to $0.9 \mathrm{Li}^{+}$based on the theoretical redox of $\mathrm{Ni}$ and $\mathrm{Ru}$ ), it is reasonable to conclude that anionic oxygen redox is not needed for charge compensation, and hence is not active in the LNRO sample. In contrast, the reversible capacity of $232 \mathrm{mAh} \mathrm{g}^{-1}$ for the LNMO sample, far beyond its theoretical value $\left(127 \mathrm{mAh} \mathrm{g}^{-1}\right)$ solely relying on $\mathrm{Ni}$ redox, implies the necessity of lattice oxygen redox in the electrochemistry. Therefore, the distinct feature observed in the $\mathrm{O} \mathrm{K}$ edge RIXS map of LNMO (but not LNRO) at $4.8 \mathrm{~V}$ charge, coupled with the fact that capacity was observed beyond that expected from the full transition-metal redox, is direct experimental evidence of reversible anionic oxygen redox in LNMO. The selection of LNMO and LNRO for anionic oxygen activity studies is largely due to the similar crystal structure as well as \# of $\mathrm{Li}^{+} / \mathrm{e}^{-}$transfer during the charge-discharge process. However, from the perspective of their redox activity, Mn4+ is difficult to be further oxidized, whereas Ru4+ is easily oxidized to Ru5+. Therefore, comparison of other Li-rich metal oxides that integrate $\mathrm{Ni}$ and a second TM with no further oxidation beyond $4+$ (e.g., $\mathrm{Zr} 4+$ or $\mathrm{Pd} 4+$ ) will be valuable as they can form monoclinic $\mathrm{Li}_{2} \mathrm{ZrO}_{3}(\mathrm{C} 2 / c)^{67}$ and $\mathrm{Li}_{2} \mathrm{PdO}_{3}(\mathrm{C} 2 / m)^{68}$, to the best of our knowledge, the electrochemistry of which are not well studied yet.

In contrast to the previously reported anionic oxygen redox in Li-, Mn-rich layered oxide, oxygen redox appeared to be suppressed in the Li-rich LNRO. Of note, no additional redox activity/capacity was revealed at a higher charge cutoff voltage $(5.0 \mathrm{~V})$ (Supplementary Fig. 4). Similar absence of anionic oxygen activity was previously observed for $\mathrm{Li}_{4} \mathrm{NiTeO}_{6} \cdot{ }^{69}$ Participation of electrons from anionic oxygen can be traced to the electronic structure of metal and oxygen (M-O) bonding, including the unique $\mathrm{Li}-\mathrm{O}-\mathrm{Li}$ configuration in Li-rich metal oxides, because certain metal bonding (e.g., Li-O-Li) can lead to unhybridized $\mathrm{O} 2 p$ states that promotes the participation of electrons from oxygen in charge compensation. ${ }^{47}$ We note the Li content in our LNRO sample is not sufficient to allow all $\mathrm{O}$ to exist in a $\mathrm{Li}-\mathrm{O}-\mathrm{Li}$ configuration, which might subsequently influence the activation of anionic oxygen in LNRO. Additionally, oxygen activation might also be inhibited by kinetic factors (e.g., particle size, cycling temperature etc.). ${ }^{70}$ However, the active anionic oxygen in LNMO, with the same Li-O-Li configuration as LNRO, confirms the crucial role that the transition metal plays in the activation of anionic oxygen. A competition between the cationic and anionic redox or inhibition of one by the other seems possible. Based on previous studies on $\mathrm{Ni}$ and $\mathrm{Ru}$ redox in structurally relevant $\mathrm{Li}$ rich metal oxides, the $\mathrm{Ru}^{4+} / \mathrm{Ru}^{5+}$ redox seems occur at a lower voltage compared to that of $\mathrm{Ni}^{2+} / \mathrm{Ni}^{3+} / \mathrm{Ni}^{4+}$. In $\mathrm{Li}_{2} \mathrm{Ru}_{1-x} \mathrm{TM}_{x} \mathrm{O}_{3}$ $(\mathrm{TM}=\mathrm{Mn}, \mathrm{Ti}$, and $\mathrm{Sn})$, these transition metals are electrochemically inactive and difficult to oxidize further up to $5+$. Therefore, there are no sufficient electrons from TM beyond $\mathrm{Ru}$ to balance the amount of $\mathrm{Li}$ extraction, driving the $\mathrm{O}$ participation in the electrochemistry. In LNRO, both $\mathrm{Ni}$ and $\mathrm{Ru}$ are electrochemically active, full oxidation of both accounts for $\mathrm{Li}$ removal. The absence of anionic oxygen activity during the removal of $1 \mathrm{Li}$ from LNRO suggests it is more difficult for the participation of electrons from oxygen than TM, because $\mathrm{O}$ redox varies with TM combinations, e.g., $4.5 \mathrm{~V}$ after Ni redox in LNMO vs. $4.3 \mathrm{~V}$ after $\mathrm{Ru}$ redox in $\mathrm{Li}_{2} \mathrm{Ru}_{1-x} \mathrm{TM}_{x} \mathrm{O}_{3}$. More transition-metal combinations, with a rational design by taking into account the transition-metal redox, should be explored in these family of Lirich layered oxides, as well as other Li-rich metal oxides that crystallize in different crystal systems, such as disordered rock salts, to further reveal the impact of $\mathrm{O}$ local environment in anionic oxygen activity. Such fundamental studies should also be extended to Li-rich metal oxides with varied $\mathrm{Li}-\mathrm{O}$ bonding beyond TM-O, therefore, both lithium content and transitionmetal composition should be taken into consideration in the design of high-capacity cathodes to utilize both conventional transition metal and anionic oxygen redox.

In summary, Li-rich metal oxides, $\mathrm{Li}_{1.2} \mathrm{Ni}_{0.2} \mathrm{TM}_{0.6} \mathrm{O}_{2}(\mathrm{TM}=$ $\mathrm{Mn}, \mathrm{Ru}$ ), demonstrate high electrochemical capacity, but the redox processes that provide this capacity are distinctly different in each material, even though the structure of each is similar. Using combined X-ray spectroscopy techniques, we illustrated the charge compensation mechanism of transition metals in both compounds and verified the electrochemical activity of $\mathrm{Ni}$ and $\mathrm{O}$ in LNMO and $\mathrm{Ni}$ and $\mathrm{Ru}$ in LNRO. In particular, a signature of anionic oxygen redox was directly observed through RIXS mapping of LNMO, whereas this signature was absent in LNRO, indicating that no such oxygen redox was active in LNRO. The unique capability of RIXS on distinguishing the photon emission energies, which is not accessible in sXAS, reveals that the key oxygen feature associated with oxygen redox is intrinsically different from the TM-O hybridization feature in emission energy, although they overlap in the sXAS spectra. By comparing materials with similar structure, our work clearly demonstrated the potential impact of transition metal on the oxygen activation in Li-rich metal oxides. We believe our findings provide additional insights into the complex oxygen redox mechanism in battery electrode beyond the conventional hybridization concept, therefore, expedite the development of advanced high-capacity Li-ion cathodes.

\section{Methods}

Synthesis of $\mathbf{L i}_{\mathbf{1 . 2}} \mathbf{N i}_{\mathbf{0 . 2}} \mathbf{T} \mathbf{M}_{\mathbf{0 . 6}} \mathbf{O}_{\mathbf{2}}(\mathbf{T M}=\mathbf{M n}, \mathbf{R u})$. Li-rich layered oxides were prepared by using $\mathrm{Li}_{2} \mathrm{CO}_{3}, \mathrm{Ni}(\mathrm{OH})_{2}, \mathrm{MnCO}_{3}$, and $\mathrm{RuO}_{2}$ as precursors, which were purchased from Sigma Aldrich. Precursors at a stoichiometric ratio of $\mathrm{Li}$ : Ni: TM $=1.2: 0.2: 0.6(\mathrm{TM}=\mathrm{Mn}, \mathrm{Ru})$ were first mixed on a Spex 8000 mill for $3 \mathrm{~h}$, followed by a calcination process at a temperature of $950{ }^{\circ} \mathrm{C}$ for $15 \mathrm{~h}$ in air.

X-ray diffraction. Powder diffractions were taken at the Advanced Photon Source at Argonne National Laboratory (ANL) on beamline 11-BM $(\lambda=0.459 \AA)$. The beamline uses a sagittal focused X-ray beam with a high precision diffractometer circle and perfect $\mathrm{Si}(111)$ crystal analyzer detection for high sensitivity and resolution. XRD patterns were analyzed by the conventional Rietveld method using the general structure analysis system package with the graphical user interface (EXPGUI). ${ }^{71}$

SEM and TEM characterization. SEM was performed on a JEOL JSM-7000F. Bright field (BF), HRTEM images, and ED patterns were obtained with a JEM$2100 \mathrm{~F}(\mathrm{JEOL})$ at an accelerating voltage of $200 \mathrm{kV}$.

X-ray absorption spectroscopy. Ex situ soft XAS measurements were carried out on beamline $10-1$ at the Stanford Synchrotron Radiation Laboratory. Data were acquired under ultrahigh vacuum $\left(10^{-9}\right.$ Torr $)$ in a single load at room temperature using TEY mode via the drain current and FY mode via a Silicon Photodiodes. RIXS maps were collected in the newly commissioned ultrahigh efficiency iRIXS endstation at Beamline 8.0.1 at the Advanced Light Sources. ${ }^{72}$ All the cycled electrodes were immediately harvested from the cells at designated cutoff voltages to minimize the side reactions between cycled electrodes and electrolyte and vigorously washed by DMC solvents to ensure the removal of soluble surface species. All the dried electrodes were transferred into the experimental vacuum chamber through a specially designed sample transfer kit in an Ar-filled glove box to avoid any air exposure. Sample surface was mounted $45^{\circ}$ to the incident beam, and the outgoing photon direction along the RIXS spectrograph is $90^{\circ}$. RIXS resolving power and other technical details could be find in our previous report. ${ }^{73}$ Details of RIXS data processing is available in supplementary information. Hard XAS measurements for the Ru K-edge was performed at the Advanced Photon Source on beamline 20-BM-B in transmission mode with electron energy of $7 \mathrm{GeV}$ and average current of $100 \mathrm{~mA}$. The radiation was monochromatized by a Si (111) 
double-crystal monochromator. Harmomic rejection was accomplished with $20 \%$ detuning. For energy calibration, the peak of the first derivative of Ru foil was adjusted to the tabulated value of $22117 \mathrm{eV}$. XANES and EXAFS data reduction and analysis were processed by Athena software.

Electrochemical characterization. Electrodes were prepared from slurries containing $80 \mathrm{wt} \%$ of active material, $10 \mathrm{wt} \%$ of polyvinylidene fluoride (PVdF) binder, and $10 \mathrm{wt} \%$ acetylene carbon black (Denka, 50\% compressed) in $\mathrm{N}$ methylpyrrolidone solvent. The slurries were casted on carbon-coated aluminum current collectors (Exopack Advanced Coatings) using a doctor blade, and then dried under vacuum at $120^{\circ} \mathrm{C}$ overnight. Typical loadings of the active materials were $\sim 2.5 \mathrm{mg} \mathrm{cm}^{-2}$. 2032-type coin cells (Hohsen Corp.) containing Li metal, a Celgard 2400 separator, and $1 \mathrm{M} \mathrm{LiPF}_{6}$ electrolyte solutions in 1:2 w/w ethylene carbonate-diethyl carbonate (Ferro Corporation) were assembled in an Ar-filled glove box $\left(\mathrm{H}_{2} \mathrm{O}<0.1 \mathrm{ppm}\right)$. Galvanostatic discharge and charge were performed on a Maccor 4200 cycler at $\mathrm{C} / 50$ between $4.8 \mathrm{~V}$ and $2.0 \mathrm{~V}$. 1C capacity was defined as $250 \mathrm{~mA} \mathrm{~g}^{-1}$.

Operando DEMS. Operando DEMS measurements were taken on a customized Swagelok type cell connected to a high-pressure gas chromatography valve. The details were described in a previous publication. ${ }^{74}$ The DEMS cell initially rested at open circuit voltage for $6 \mathrm{~h}$ and charge/discharge was done under potentiostatic control using a BioLogic SP-300 potentiostat.

Data availability. The data that support the findings of this study are available from the corresponding authors upon reasonable request.

Received: 21 July 2017 Accepted: 12 February 2018

Published online: 05 March 2018

\section{References}

1. Whittingham, M. S. Lithium batteries and cathode materials. Chem. Rev. 104, 4271-4301 (2004).

2. Goodenough, J. B. \& Kim, Y. Challenges for rechargeable Li batteries. Chem. Mater. 22, 587-603 (2010).

3. Etacheri, V., Marom, R., Elazari, R., Salitra, G. \& Aurbach, D. Challenges in the development of advanced Li-ion batteries: a review. Energ. Environ. Sci. 4, 3243-3262 (2011).

4. Andre, D. et al. Future generations of cathode materials: an automotive industry perspective. J. Mater. Chem. A 3, 6709-6732 (2015).

5. Liu, W. et al. Nickel-rich layered lithium transition-metal oxide for high-energy lithium-ion batteries. Angew. Chem. Int. Ed. 54, 4440-4457 (2015).

6. Manthiram, A., Knight, J. C., Myung, S.-T., Oh, S.-M. \& Sun, Y.-K. Nickel-rich and lithium-rich layered oxide cathodes: progress and perspectives. $A d v$. Energy Mater. 6, 1501010 (2016).

7. Xu, J., Lin, F., Doeff, M. M. \& Tong, W. A review of Ni-based layered oxides for rechargeable Li-ion batteries. J. Mater. Chem. A 5, 874-901 (2017).

8. Hy, S. et al. Performance and design considerations for lithium excess layered oxide positive electrode materials for lithium ion batteries. Energ. Environ. Sci. 9, 1931-1954 (2016).

9. Jeom-Soo, K. et al. Electrochemical and structural properties of $\mathrm{xLi}_{2} \mathrm{M}^{\prime} \mathrm{O}_{3}$. (1-x) $\mathrm{LiMn}_{0.5} \mathrm{Ni}_{0.5} \mathrm{O}_{2}$ electrodes for lithium batteries $\left(\mathrm{M}^{\prime}=\mathrm{Ti}, \mathrm{Mn}, \mathrm{Zr} ; 0<\mathrm{x}\right.$ <0.3). Chem. Mater. 16, 1996-2006 (2004).

10. Thackeray, M. M., Johnson, C. S., Vaughey, J. T., Li, N. \& Hackney, S. A Advances in manganese-oxide 'composite' electrodes for lithium-ion batteries. J. Mater. Chem. 15, 2257-2267 (2005).

11. Thackeray, M. M. et al. $\mathrm{Li}_{2} \mathrm{MnO}_{3}$-stabilized $\mathrm{LiMO}_{2}(\mathrm{M}=\mathrm{Mn}, \mathrm{Ni}, \mathrm{Co})$ electrodes for lithium-ion batteries. J. Mater. Chem. 17, 3112-3125 (2007).

12. Lu, Z., MacNeil, D. D. \& Dahn, J. R. Layered cathode materials Li [NixLi $\left.{ }_{3-2 \mathrm{x} / 3)} \mathrm{Mn}_{(2 / 3-\mathrm{x} / 3)}\right] \mathrm{O}_{2}$ for lithium-ion batteries. Electrochem. Solid-State Lett. 4, A191-A194 (2001)

13. Lu, Z. H., Beaulieu, L. Y., Donaberger, R. A., Thomas, C. L. \& Dahn, J. R. Synthesis, structure, and electrochemical behavior of $\mathrm{LiNixLi}_{1 / 3-2 \mathrm{x} / 3} \mathrm{Mn}_{2 / 3-\mathrm{x} /}$ ${ }_{3} \mathrm{O}_{2}$. J. Electrochem. Soc. 149, A778-A791 (2002).

14. Lu, Z. H. \& Dahn, J. R. Understanding the anomalous capacity of $\mathrm{Li} / \mathrm{LiNi}_{\mathrm{x}} \mathrm{Li}_{(1 /}$ $3-2 \mathrm{x} / 3) \mathrm{Mn}_{(2 / 3-\mathrm{x} / 3)} \mathrm{O}_{2}$ cells using in situ X-ray diffraction and electrochemical studies. J. Electrochem. Soc. 149, A815-A822 (2002).

15. Shukla, A. K. et al. Unravelling structural ambiguities in lithium- and manganese-rich transition metal oxides. Nat. Comm. 6, 8711 (2015).

16. Armstrong, A. R. et al. Demonstrating oxygen loss and associated structural reorganization in the lithium battery cathode $\mathrm{LiNi}_{0.2} \mathrm{Li}_{0.2} \mathrm{Mn}_{0.6} \mathrm{O}_{2}$. J. $A m$. Chem. Soc. 128, 8694-8698 (2006).
17. Wu, Y. \& Manthiram, A. High capacity, surface-modified layered Li $\left[\mathrm{Li}_{(1-\mathrm{x}) / 3} \mathrm{Mn}_{(2-\mathrm{x})} / 3 \mathrm{Ni}_{\mathrm{x} / 3} \mathrm{Co}_{\mathrm{x} / 3}\right] \mathrm{O}_{2}$ cathodes with low irreversible capacity loss. Electrochem. Solid-State Lett. 9, A221-A224 (2006).

18. Johnson, C. S., Li, N. C., Lefief, C. \& Thackeray, M. M. Anomalous capacity and cycling stability of $\mathrm{xLi}_{2} \mathrm{MnO}_{3} \cdot(1-\mathrm{x}) \mathrm{LiMO}_{2}$ electrodes $(\mathrm{M}=\mathrm{Mn}, \mathrm{Ni}, \mathrm{Co})$ in lithium batteries at $50^{\circ} \mathrm{C}$. Electrochem. Commun. 9, 787-795 (2007).

19. Takahashi, Y. et al. Development of lithium-ion batteries with a $\mathrm{LiCoO}_{2}$ cathode toward high capacity by elevating charging potential. J. Electrochem. Soc. 155, A537-A541 (2008).

20. Jiang, M., Key, B., Meng, Y. S. \& Grey, C. P. Electrochemical and structural study of the layered, "Li-excess" lithium-ion battery electrode material $\mathrm{LiLi}_{1 /}$ ${ }_{9} \mathrm{Ni}_{1 / 3} \mathrm{Mn}_{5 / 9} \mathrm{O}_{2}$. Chem. Mater. 21, 2733-2745 (2009).

21. Kang, S. H. \& Thackeray, M. M. Enhancing the rate capability of high capacity $\mathrm{xLi}_{2} \mathrm{MnO}_{3} \cdot(1-\mathrm{x}) \mathrm{LiMO}_{2}(\mathrm{M}=\mathrm{Mn}, \mathrm{Ni}, \mathrm{Co})$ electrodes by Li-Ni-PO4 treatment Electrochem. Commun. 11, 748-751 (2009).

22. Fu, F. et al. Structure dependent electrochemical performance of Li-rich layered oxides in lithium-ion batteries. Nano Energy 35, 370-378 (2017)

23. Hong, J. et al. Critical role of oxygen evolved from layered Li-excess metal oxides in lithium rechargeable batteries. Chem. Mater. 24, 2692-2697 (2012).

24. Castel, E., Berg, E. J., El Kazzi, M., Novák, P. \& Villevieille, C. Differential electrochemical mass spectrometry study of the interface of $\mathrm{xLi}_{2} \mathrm{MnO}_{3} \bullet(1-\mathrm{x})$ $\mathrm{LiMO}_{2}(\mathrm{M}=\mathrm{Ni}, \mathrm{Co}$, and $\mathrm{Mn})$ material as a positive electrode in $\mathrm{Li}$-ion batteries. Chem. Mater. 26, 5051-5057 (2014).

25. Qian, D., Xu, B., Chi, M. \& Meng, Y. S. Uncovering the roles of oxygen vacancies in cation migration in lithium excess layered oxides. Phys. Chem. Chem. Phys. 16, 14665-14668 (2014).

26. Hy, S., Su, W.-N., Chen, J.-M. \& Hwang, B.-J. Soft X-ray absorption spectroscopic and Raman studies on $\mathrm{Li}_{1.2} \mathrm{Ni}_{0.2} \mathrm{Mn}_{0.6} \mathrm{O}_{2}$ for lithium-ion batteries. J. Phys. Chem. C. 116, 25242-25247 (2012).

27. $\mathrm{Hy}, \mathrm{S}$. et al. Understanding the role of $\mathrm{Ni}$ in stabilizing the lithium-rich highcapacity cathode material $\mathrm{Li}\left[\mathrm{NixLi}_{(1-2 \mathrm{x}) / 3} \mathrm{Mn}_{(2-\mathrm{x}) / 3}\right] \mathrm{O}_{2}(0 \leq \mathrm{x} \leq 0.5)$. Chem. Mater. 26, 6919-6927 (2014).

28. Oishi, M. et al. Direct observation of reversible oxygen anion redox reaction in Li-rich manganese oxide, $\mathrm{Li}_{2} \mathrm{MnO}_{3}$, studied by soft X-ray absorption spectroscopy. J. Mater. Chem. A 4, 9293-9302 (2016).

29. Yabuuchi, N., Yoshii, K., Myung, S.-T., Nakai, I. \& Komaba, S. Detailed studies of a high-capacity electrode material for rechargeable batteries, $\mathrm{Li}_{2} \mathrm{MnO}_{3} \cdot \mathrm{LiCo}_{1 / 3} \mathrm{Ni}_{1 / 3} \mathrm{Mn}_{1 / 3} \mathrm{O}_{2}$. J. Am. Chem. Soc. 133, 4404-4419 (2011).

30. Hy, S., Felix, F., Rick, J., Su, W. N. \& Hwang, B. J. Direct in situ observation of $\mathrm{Li}_{2} \mathrm{O}$ evolution on Li-rich high-capacity cathode material, $\operatorname{LiNixLi}_{(1-2 \mathrm{x}) /}$ ${ }_{3} \mathrm{Mn}_{(2-\mathrm{x}) / 3} \mathrm{O}_{2}(0 \leq \mathrm{x} \leq 0.5)$. J. Am. Chem. Soc. 136, 999-1007 (2014).

31. Koga, H. et al. Reversible oxygen participation to the redox processes revealed for $\mathrm{Li}_{1.20} \mathrm{Mn}_{0.54} \mathrm{Co}_{0.13} \mathrm{Ni}_{0.13} \mathrm{O}_{2}$. J. Electrochem. Soc. 160, A786-A792 (2013).

32. Koga, H. et al. Different oxygen redox participation for bulk and surface: a possible global explanation for the cycling mechanism of $\mathrm{Li}_{1.20} \mathrm{Mn}_{0.54} \mathrm{Co}_{0.13} \mathrm{Ni}_{0.13} \mathrm{O}_{2}$. J. Power Sources 236, 250-258 (2013)

33. Assat, G., Delacourt, C., Corte, D. A. D. \& Tarascon, J.-M. Practical assessment of anionic redox in Li-rich layered oxide cathodes: a mixed blessing for high energy Li-ion batteries. J. Electrochem. Soc. 163, A2965-A2976 (2016).

34. Delmas, C. Battery materials: operating through oxygen. Nat. Chem. 8, 641-643 (2016).

35. Grimaud, A., Hong, W. T., Shao-Horn, Y. \& Tarascon, J. M. Anionic redox processes for electrochemical devices. Nat. Mater. 15, 121-126 (2016).

36. Qiu, B. et al. Gas-solid interfacial modification of oxygen activity in layered oxide cathodes for lithium-ion batteries. Nat. Commun. 7, 12108 (2016).

37. Qiu, B., Zhang, M., Xia, Y., Liu, Z. \& Meng, Y. S. Understanding and controlling anionic electrochemical activity in high-capacity oxides for next generation Li-ion batteries. Chem. Mater. 29, 908-915 (2017).

38. Zhao, C. et al. Review on anionic redox for high-capacity lithium- and sodium-ion batteries. J. Phys. D. Appl. Phys. 50, 183001 (2017).

39. Sathiya, M. et al. High performance $\mathrm{Li}_{2} \mathrm{Ru}_{1-\mathrm{y}} \mathrm{Mn}_{\mathrm{y}} \mathrm{O}_{3}(0.2 \leq \mathrm{y} \leq 0.8)$ cathode materials for rechargeable lithium-ion batteries: their understanding. Chem. Mater. 25, 1121-1131 (2013).

40. Sathiya, M. et al. Reversible anionic redox chemistry in high-capacity layeredoxide electrodes. Nat. Mater. 12, 827-835 (2013).

41. McCalla, E. et al. Visualization of O-O peroxo-like dimers in high-capacity layered oxides for Li-ion batteries. Science 350, 1516-1521 (2015).

42. McCalla, E. et al. Reversible Li-intercalation through oxygen reactivity in Lirich Li-Fe-Te oxide materials. J. Electrochem. Soc. 162, A1341-A1351 (2015)

43. McCalla, E. et al. Understanding the roles of anionic redox and oxygen release during electrochemical cycling of lithium-rich layered $\mathrm{Li}_{4} \mathrm{FeSbO}_{6}$. J. Am. Chem. Soc. 137, 4804-4814 (2015).

44. Sathiya, M. et al. Origin of voltage decay in high-capacity layered oxide electrodes. Nat. Mater. 14, 230-238 (2015).

45. Luo, K. et al. Anion redox chemistry in the cobalt free $3 \mathrm{~d}$ transition meta oxide intercalation electrode $\mathrm{LiLi}_{0.2} \mathrm{Ni}_{0.2} \mathrm{Mn}_{0.6} \mathrm{O}_{2}$. J. Am. Chem. Soc. 138, 11211-11218 (2016). 
46. Luo, K. et al. Charge-compensation in 3d-transition-metal-oxide intercalation cathodes through the generation of localized electron holes on oxygen. Nat. Chem. 8, 684-691 (2016).

47. Seo, D.-H. et al. The structural and chemical origin of the oxygen redox activity in layered and cation-disordered Li-excess cathode materials. Nat. Chem. 8, 692-697 (2016).

48. Miura, Y., Yasui, Y., Sato, M., Igawa, N. \& Kakurai, K. New-type phase transition of $\mathrm{Li}_{2} \mathrm{RuO}_{3}$ with honeycomb structure. J. Phys. Soc. Jpn. 76, 033705 (2007).

49. Knight, J. C., Nandakumar, P., Kan, W. H. \& Manthiram, A. Effect of Ru substitution on the first charge-discharge cycle of lithium-rich layered oxides. J. Mater. Chem. A 3, 2006-2011 (2015).

50. $\mathrm{Li}, \mathrm{B}$. et al. Lithium-ion batteries: understanding the stability for Li-rich layered oxide $\mathrm{Li}_{2} \mathrm{RuO}_{3}$ cathode. Adv. Funct. Mater. 26, 1306-1306 (2016)

51. Li, B., Yan, H., Zuo, Y. \& Xia, D. Tuning the reversibility of oxygen redox in lithium-rich layered oxides. Chem. Mater. 29, 2811-2818 (2017).

52. Jung, R., Metzger, M., Maglia, F., Stinner, C. \& Gasteiger, H. A. Chemical versus electrochemical electrolyte oxidation on NMC111, NMC622, NMC811, LNMO, and Conductive Carbon. J. Phys. Chem. Lett. 8, 4820-4825 (2017).

53. Streich, D. et al. Operando monitoring of early Ni-mediated surface reconstruction in layered lithiated Ni-Co-Mn oxides. J. Phys. Chem. C. 121, 13481-13486 (2017).

54. Qinghao, L. et al. Quantitative probe of the transition metal redox in battery electrodes through soft x-ray absorption spectroscopy. J. Phys. D. Appl. Phys. 49, 413003 (2016).

55. Qiao, R. et al. Direct experimental probe of the $\mathrm{Ni}(\mathrm{II}) / \mathrm{Ni}(\mathrm{III}) / \mathrm{Ni}(\mathrm{IV})$ redox evolution in $\mathrm{LiNi}_{0.5} \mathrm{Mn}_{1.5} \mathrm{O}_{4}$ electrodes. J. Phys. Chem. C. 119, 27228-27233 (2015).

56. Liu, X. et al. Distinct charge dynamics in battery electrodes revealed by in situ and operando soft X-ray spectroscopy. Nat. Commun. 4, 2568 (2013).

57. Yoon, W.-S. et al. Investigation of the charge compensation mechanism on the electrochemically Li-ion deintercalated $\mathrm{Li}_{1-\mathrm{x}} \mathrm{Co}_{1 / 3} \mathrm{Ni}_{1 / 3} \mathrm{Mn}_{1 / 3} \mathrm{O}_{2}$ electrode system by combination of soft and hard X-ray absorption spectroscopy. J. Am. Chem. Soc. 127, 17479-17487 (2005).

58. Suntivich, J. et al. Estimating hybridization of transition metal and oxygen states in perovskites from O K-edge X-ray absorption spectroscopy. J. Phys Chem. C. 118, 1856-1863 (2014).

59. Liu, X. et al. Why $\mathrm{LiFePO}_{4}$ is a safe battery electrode: Coulomb repulsion induced electron-state reshuffling upon lithiation. Phys. Chem. Chem. Phys. 17, 26369-26377 (2015).

60. Mortemard de Boisse, B. et al. Intermediate honeycomb ordering to trigger oxygen redox chemistry in layered battery electrode. Nat. Commun. 7, 11397 (2016).

61. Kotani, A. \& Shin, S. Resonant inelastic x-ray scattering spectra for electrons in solids. Rev. Mod. Phys. 73, 203-246 (2001).

62. Devereaux, T. P. \& Hackl, R. Inelastic light scattering from correlated electrons. Rev. Mod. Phys. 79, 175-233 (2007).

63. Butorin, S. M., Guo, J., Wassdahl, N. \& Nordgren, E. J. Tunable-excitation soft $\mathrm{X}$-ray fluorescence spectroscopy of high-Tc superconductors: an inequivalentsite seeing story. J. Electron Spectrosc. Relat. Phenom. 110, 235-273 (2000).

64. Glans, P. et al. Resonant X-ray emission spectroscopy of molecular oxygen. Phys. Rev. Lett. 76, 2448-2451 (1996).

65. Hennies, F. et al. Resonant inelastic scattering spectra of free molecules with vibrational resolution. Phys. Rev. Lett. 104, 193002 (2010).

66. Kim, J. S. et al. Valence state of $\mathrm{Ru}$ at the $\mathrm{Mn}$ sites in $\mathrm{Pr}_{0.5} \mathrm{Sr}_{0.5} \mathrm{MnO}_{3}$ : thermoelectric power and X-ray absorption near-edge structure spectroscopy. J. Supercon. Nov. Magn. 17, 183-186 (2004).

67. Ochoa-Fernández, E., Rønning, M., Grande, T. \& Chen, D. Synthesis and $\mathrm{CO}_{2}$ capture properties of nanocrystalline lithium zirconate. Chem. Mater. 18, 6037-6046 (2006).

68. Kim, S. et al. Material design of high-capacity Li-rich layered-oxide electrodes: Li2MnO3 and beyond. Energ. Environ. Sci. 10, 2201-2211 (2017).

69. Sathiya, M. et al. $\mathrm{Li}_{4} \mathrm{NiTeO}_{6}$ as a positive electrode for $\mathrm{Li}$-ion batteries. Chem. Commun. 49, 11376-11378 (2013).

70. Zhang, L. et al. Synthesis and electrochemistry of cubic rocksalt Li-Ni-Ti-O compounds in the phase diagram of $\mathrm{LiNiO}_{2}-\mathrm{LiTiO}_{2}-\mathrm{Li}\left[\mathrm{Li}_{1 / 3} \mathrm{Ti}_{2 / 3}\right] \mathrm{O}_{2}$. J. Power Sources 185, 534-541 (2008).
71. Toby, B. EXPGUI, a graphical user interface for GSAS. J. Appl. Crystallogr. 34, 210-213 (2001).

72. Qiao, R. et al. Modular soft x-ray spectrometer for applications in energy sciences and quantum materials. Rev. Sci. Instrum. 88, 033106 (2017)

73. Chuang, Y.-D. et al. Modular soft x-ray spectrometer for applications in energy sciences and quantum materials. Rev. Sci. Instrum. 88, 013110 (2017).

74. McCloskey, B. D., Bethune, D. S., Shelby, R. M., Girishkumar, G. \& Luntz, A C. Solvents' critical role in nonaqueous lithium-oxygen battery electrochemistry. J. Phys. Chem. Lett. 2, 1161-1166 (2011)

\section{Acknowledgements}

This work was supported by the Assistant Secretary for Energy Efficiency and Renewable Energy, Office of Vehicle Technologies of the U.S. Department of Energy under Contract No. DE-AC02-05CH11231. S.E.R. gratefully acknowledges support from the Department of Defense (DOD) through the National Defense Science \& Engineering Graduate Fellowship (NDSEG) Program. This research used resources of the Advanced Light Source, which is a DOE Office of Science User Facility under contract no. DE-AC02-05CH11231 Use of the Stanford Synchrotron Radiation Lightsource, SLAC National Accelerator Laboratory, is supported by the U.S. Department of Energy, Office of Science, Office of Basic Energy Sciences under Contract No. DE-AC02-76SF00515. Use of the Advanced Photon Source at Argonne National Laboratory was supported by the U. S. Department of Energy, Office of Science, Office of Basic Energy Sciences, under Contract No. DEAC02-06CH11357. Electron microscopy work was performed at the Center for Functional Nanomaterials, Brookhaven National Laboratory, which is supported by the U.S Department of Energy (DOE), Office of Basic Energy Science, under contract DESC0012704. W.T. appreciates the useful discussion on hard XAS with Dr. Matthew A. Marcus, Lawrence Berkeley National Laboratory.

\section{Author Contributions}

W.T. designed the experiments. J. X. and M. S. conducted material synthesis, performed physical, and electrochemical characterization and analysis. S.H. and D.S. performed TEM experiments and analysis. S.E.R. and B.D.M. performed gas evolution measurements and analysis. D.N. recorded sXAS data. R.Q. and W. Y. collected and analyzed RIXS data. L.M., T.W., K.A., and J.L. carried out hard XAS experiment and analysis. J.X. and W.T. wrote the manuscript and all authors contributed to the discussion and provided feedback on the manuscript.

\section{Additional information}

Supplementary Information accompanies this paper at https://doi.org/10.1038/s41467 018-03403-9.

Competing interests: The authors declare no competing interests.

Reprints and permission information is available online at http://npg.nature.com/ reprintsandpermissions/

Publisher's note: Springer Nature remains neutral with regard to jurisdictional claims in published maps and institutional affiliations.

Open Access This article is licensed under a Creative Commons Attribution 4.0 International License, which permits use, sharing, adaptation, distribution and reproduction in any medium or format, as long as you give appropriate credit to the original author(s) and the source, provide a link to the Creative Commons license, and indicate if changes were made. The images or other third party material in this article are included in the article's Creative Commons license, unless indicated otherwise in a credit line to the material. If material is not included in the article's Creative Commons license and your intended use is not permitted by statutory regulation or exceeds the permitted use, you will need to obtain permission directly from the copyright holder. To view a copy of this license, visit http://creativecommons.org/ licenses/by/4.0/.

(c) The Author(s) 2018 